\title{
LA BUENA FE EN LOS CONTRATOS INTERNACIONALES
}

\author{
Mario RAMÍREZ NECOCHEA*
}

RESUMEN: El trabajo se estructura en torno al importante papel que representa la buena fe ante el cumplimiento de los contratos, frente a la seguridad contractual. En una primera parte esto se analiza a partir de reflexiones generales e históricas relativas a la ambigüedad e imprecisión del concepto de la buena fe; en una segunda parte, se estudia el alcance interpretativo de dicho principio dentro de algunos casos de codificación a nivel nacional, la Convención de Viena, y los Principios de Unidroit.

ABSTRACT: This work is structured around the important role that good faith plays in the performance of contracts, in relation to contractual certainty. In the first part of the article, this is analyzed from the perspective of general and historical reflections on the ambiguity and vagueness of the concept of good faith; in the second part, the author considers the interpretative influence of that principle within various national codes, the Vienna Convention and the Unidroit principles.

RÉSUMÉ: Cet article se déroule autour de l'important rôle du bonne foi dans l'execution des contrats par rapport à la sécurité contractuelle. Dans une première partie, ce téme est analysé a partir des reflections générales et historiques sur l'ambigüité et imprecisión du concepte de bonne foi. Dans une seconde partie, on trouve l'atteinte interpretative de ce principle dans quelques cases de codification au niveau national, la Convention de Vienne et les principles de l'Unidroit.

* Profesor titular de la Facultad de Derecho de la Universidad de Chile, director del Departamento de Derecho Internacional. 
SUMARIO: I. Ideas generales. II. Los códigos de Bello y de Vélez Sarsfield. III. La buena fe en la Convención de Viena sobre Compraventa Internacional de Mercaderías y en los Principios de Unidroit. IV. Conclusiones.

\section{IDEAS GENERALES}

La buena fe en los contratos se traduce en la honestidad y lealtad que debe imperar entre las partes. Este concepto es impreciso porque apunta a la conducta humana, que tiene muy diversos matices; y además, porque se aplica en sentidos muy diferentes, que varían según la visión que tengamos de la relación contractual.

Nuestro trabajo tiene por objeto analizar el dilema principal que nos plantea esta ambigüedad y que puede sintetizarse en dos pasajes del $\mathrm{Di}$ gesto: ${ }^{1}$ Primero, la buena fe exige que se cumpla lo convenido (D.19.2.21); y segundo, la buena fe que se exige en los contratos requiere la máxima equidad (D.16.3.31).

En el primer caso, la buena fe consiste en la honestidad necesaria para cumplir con la palabra empeñada; la obligación debe cumplirse, aunque resulte ruinosa para el deudor, o no guarde relación alguna con el valor de lo que reciba a cambio. Esta posición se fundamenta en que los hombres son libres e iguales; y por consiguiente, los compromisos que contraigan ejerciendo los atributos indicados, son justos. Por otra parte, la vida de los negocios depende, en gran medida, de la seguridad que da la intangibilidad de los contratos.

En el segundo caso, la buena fe consiste en que cada contratante busque su propio beneficio, pero respetando leal y honestamente los intereses del otro. Cuando falta ese referente moral, el juez puede modificar el contrato en función de diversos conceptos relacionados con la buena fe, y que se manejan en el derecho moderno: La excesiva onerosidad al contratar o por causa sobreviniente; el abuso del derecho, no ir en contra de un hecho propio; el enriquecimiento sin causa o la frustración de la finalidad del negocio.

Esta facultad del juez no es novedosa, puesto que se encuentra ya en el derecho romano: "Las acciones de buena fe van a surgir en el ámbito de la contratación romana cuando se puso como criterio determinante en

1 Versión de D'Ors et al., Digesto, Pamplona, Aranzadi, 1968. 
las relaciones obligatorias la buena fe. Al estar basadas en la confianza mutua, en las reglas de corrección del tráfico, el juez tiene un gran campo de discrecionalidad, pudiendo medir las responsabilidades de las partes, valorando su conducta en el negocio realizado". ${ }^{2}$

Además, debemos recordar la Gran ética de Aristóteles, que exige que "nuestro trato mutuo tenga lugar en igualdad de condiciones". ${ }^{3}$ Es cierto que los hombres son iguales en su dignidad como tales; pero existen grandes diferencias en sus condiciones para negociar, lo que puede traducirse en relaciones contractuales desproporcionadas y abusivas.

A pesar de esta realidad, la idea de incorporar la buena fe como regla general en el derecho de los contratos no carece de opositores; así, por ejemplo, el profesor argentino Vernengo ${ }^{4}$ abunda sobre los defectos y peligros que tiene acoger un principio "tan vago y ambiguo"; y el profesor peruano De Traseignes nos da este juicio lapidario:

Desde la perspectiva de la sociedad de mercado, negar a los contratantes la capacidad para engendrar por sí mismos maduramente derechos y obligaciones correlativas en lo que no está prohibido por la ley con el argumento de que las decisiones adoptadas al momento de celebrar el contrato atentan ahora contra la equidad y la buena fe, es deformar el cuerpo social y hacer imposible la predicción y el cálculo que son condiciones sine qua non del ejercicio de la libertad y de la garantía de eficiencia de las acciones dentro de este medio social. La equidad y la buena fe - con la vaguedad implícita a la que he hecho referencia- se convierten aquí en los agentes terroristas de la seguridad contractual. ${ }^{5}$

Por otro lado, el common law tradicional es muy reacio a incorporar reglas generales en su ordenamiento jurídico, porque éste se estructura, a la inversa, sobre la base de los casos concretos; y específicamente sobre la buena fe, un fallo inglés de 1992, expresa lo siguiente: "El concepto de un deber de negociar de buena fe es inherentemente repugnante a la posición de partes adversarias-contrarias, envueltas en negociaciones. Cada

2 Louzan, Nelly, "La buena fe en el derecho romano", en varios autores, Tratado de la buena fe en el derecho, Buenos Aires, La Ley, 2004, t. I, p. 82.

3 Aristóteles, Gran ética, Altamira, España, 1984, p. 91.

4 Vernengo, Roberto, "Los principios de la buena fe", en varios autores, op. cit., nota 2, pp. 27-32.

5 Traseignes, Fernando de, "Desacralizando la buena fe en el derecho", en varios autores, $o p$. cit., nota 2, p. 43. 
parte en una negociación tiene derecho a proseguir su propio interés, mientras evite hacer falsas representaciones. Un deber de negociar de buena fe es tan impráctico como inconsistente con la posición de las partes negociadoras". ${ }^{6}$

Sin embargo, tanto el Código Uniforme de Comercio como el Segundo Restatement de Contratos de EUA contemplan el deber de la buena fe, en la ejecución y en el cumplimiento del contrato; además, ese país cuenta con una serie de herramientas jurídicas para enfrentar una conducta abusiva en la etapa de la formación del contrato. ${ }^{7} \mathrm{Y}$ una tendencia semejante se encuentra en Australia, Nueva Zelanda y Canadá.

Con estas ideas generales, veremos brevemente cómo se resuelve el dilema que hemos expuesto, primero en dos códigos de derechos nacionales que han tenido distinto grado de evolución en materia de buena fe contractual; segundo, en la Convención de Viena sobre Compraventa Internacional de Mercaderías y, tercero, en los Principios de Unidroit.

Tomamos a los dos primeros porque los derechos nacionales regulan también a los contratos internacionales cuando opera el mecanismo de elección de ley; a la Convención de Viena, porque regula el principal de los contratos del comercio internacional; y a los Principios de Unidroit porque constituyen una verdadera codificación de prácticas y de convicciones doctrinarias relativas a la contratación internacional.

\section{LOS CÓDIGOS DE BELLO Y DE VÉLEZ SARSFIELD}

El artículo 1546 del Código de Bello de 1855, señala que "los contratos deben ejecutarse de buena fe, y por consiguiente obligan no sólo a lo que en ellos se expresa, sino a todas las cosas que emanan precisamente de la naturaleza de la obligación, o que por ley o la costumbre pertenecen a ella".

Este artículo utiliza la expresión "de buena fe" en el sentido de que se debe cumplir con la obligación prometida en forma íntegra; "y por consiguiente", con todo lo que explícita o implícitamente le corresponde de acuerdo con los términos del contrato, la naturaleza de obligación, la ley o la costumbre. De este modo, el artículo 1546 acoge la buena fe en

6 Citado por Silva, Pedro, "La buena fe en la Convención de Viena sobre compraventa internacional de mercaderías", en varios autores, op. cit., nota 2, p. 367.

7 Unconscionability, misrepresentation, false representation, etcétera. 
un sentido estrecho, sin referirse a ella como una regla general con capacidad para modificar obligaciones injustas.

La jurisprudencia tradicional, por su parte, apegada al texto de la ley, ha dado sólo "pasos tímidos y cautelosos" en cuanto a utilizar este principio como un correctivo ético. ${ }^{8}$

La doctrina ha sido más avanzada; así, por ejemplo, Fernando Fueyo sostiene que la buena fe permite fijar "en su verdadera extensión y medida la obligación por cumplir. La sujeción a la buena fe viene a ser una máxima ético-jurídica". Y agrega que "el juez aplicará el principio general de la buena fe en forma amplia y extendida, hasta alcanzar e integrar la norma positiva de que dispone o bien creará razonablemente la norma aún contra legem". 9

Don Andrés Bello tenía una visión opuesta, ya que no era partidario de incorporar ninguna regla abierta al artículo 1546; por este motivo, excluyó la referencia a la equidad que hace el artículo 1135 del Código de Napoleón que le sirvió de modelo. Incluso es posible, como señala Alejandro Guzmán, "que haya concebido el temor de dejar en manos del juez un instrumento de revisión de los contratos en sentido extensivo demasiado peligroso". ${ }^{10}$

El Código de Vélez Sársfield de 1869, en su artículo 1198, estableció que "los contratos obligan no sólo a lo que está formalmente expresado en ellos, sino a todas las consecuencias que puedan considerarse que hubiesen sido virtualmente comprendidas en ellos".

Es legítimo considerar que entre esas consecuencias, se encuentran las que se deriven de la buena fe, puesto que este principio "impera en todo el derecho, aunque no se le mencione". ${ }^{11}$ De esta manera, se concibió que se podía dar al artículo 1198 una fuerza expansiva, aunque no usara la expresión "de buena fe", en la forma expresa con que ésta se fue incorporando en diversos códigos europeos; entre estos últimos, se debe destacar el artículo 242 del Código Alemán de 1900, que dio origen a

8 Corral, Hernán ,"La aplicación jurisprudencial de la buena fe objetiva en el ordenamiento civil chileno", en varios autores, op. cit., nota 2, p. 224.

9 Fueyo, Fernando, Instituciones de derecho civil moderno, Editorial Jurídica de Chile, 1990, pp. 153 y 161 .

10 "La buena fe en el Código Civil de Chile", en varios autores, op. cit., nota 2, p. 86.

11 Gastaldi, José, "La buena fe en el derecho de los contratos. Su consagración desde el Código Civil de Vélez Sársfield”, en varios autores, op. cit., nota 2, p. 311. 
una jurisprudencia de avanzada, y el artículo 1337 del Código Italiano de 1942.

Siguiendo estos ejemplos, Argentina modificó en 1968 su Código Civil, y dejó el artículo 1198 con la siguiente redacción: "Los contratos deben celebrarse, interpretarse y ejecutarse de buena fe y de acuerdo con lo que verosímilmente las partes entendieron o pudieron entender, obrando con cuidado y previsión".

La aplicación más clara de este precepto la encontramos en un fallo de 1986 que expresa: "La observación de la buena fe objetiva (lealtad) por parte de los contratantes (acreedor y deudor) significa que el acreedor no debe pretender más, en el ejercicio de su crédito, ni el deudor pretender dar menos, en el cumplimiento de su obligación, de lo que exige el sentido de la probidad, habida cuenta de la finalidad del contrato". ${ }^{12}$

Pero la evolución ha continuado, puesto que se encuentra pendiente un nuevo proyecto de reforma del Código Civil argentino, que acogería en forma aún más amplia el principio de la buena fe.

\section{LA BUENA FE EN LA CONVENCIÓN DE VIENA SOBRE COMPRAVENTA INTERNACIONAL DE MERCADERÍAS Y EN LOS PRINCIPIOS DE UNIDROIT}

La convención contempla la buena fe en su artículo 7.1 que expresa: "En la interpretación de la presente convención se tendrán en cuenta su carácter internacional y la necesidad de promover la uniformidad en su aplicación y de asegurar la observancia de la buena fe en el comercio internacional". Como se ve, esta disposición se refiere a la interpretación de la convención misma, y no de los contratos de compraventa que se celebren en virtud de ella.

Pero dentro de ese marco, se considera necesario asegurar la observancia de la buena fe en el comercio internacional; y como esta actividad se realiza justamente a través de los contratos, se podría deducir que, para la convención, la necesidad de la buena fe se extendería también a estos últimos.

Sin embargo, debemos convenir que el contenido de este artículo es ambiguo; y es así porque surgió como fórmula de compromiso entre los

12 Aldana Acosta vs. Camba Fernández, CNCiv., 1986.08.14, en varios autores, op. cit., nota 2, p. 461. 
países que deseaban una norma general sobre la buena fe aplicable a los contratos, y los que no la aceptaban por que introduciría un factor de incertidumbre y de riesgosa sumisión al arbitrio judicial. En otras palabras, se vio en la Convención de Viena el mismo dilema que estamos analizando en este trabajo, y que deben enfrentar los tribunales al momento de enfrentarlo.

Elina Mereminskaya, profesora rusa de la Universidad de Chile, analizó justamente el tema en su artículo sobre la buena fe contractual en la jurisprudencia chilena e internacional. ${ }^{13}$ De acuerdo con ese trabajo, los tribunales chilenos no han tenido ocasión de aplicar el artículo 7.1 de la Convención de Viena; en cambio, hay numerosos fallos internacionales, principalmente dictados en Alemania y en Austria, que lo han invocado para aplicar el principio de la buena fe.

La profesora Mereminskaya ha encontrado varias sentencias chilenas que han acogido, en los últimos años, el principio de la buena fe en contratos internos relacionados principalmente con el trabajo y la salud; y considera que los fallos extranjeros señalados facilitarán la misma solución respecto de los contratos internacionales, por cuanto el artículo 7.1 de la convención, que fue ratificada por Chile en 1990, exige su aplicación uniforme.

Donde no encontramos ninguna ambigüedad es en el artículo 1.7 de los Principios de Unidroit para los contratos mercantiles internacionales que establece lo siguiente: a) Las partes deben actuar con buena fe $\mathrm{y}$ lealtad negocial en el comercio internacional; $b$ ) Las partes no pueden excluir ni limitar este deber.

\section{CONCLUSIONES}

Conforme con lo anteriormente expuesto, la aceptación creciente del principio general de buena fe puede observarse en cuatro niveles. Primero, los países del common law han ido perdiendo su resistencia ante este concepto, siendo Inglaterra el único país que sigue rechazando la buena fe como canon general de conducta. Segundo, los países de tradición romanista, de Código Civil, han ido incorporando progresivamente esta norma con carácter abierto. Tercero, el artículo ambiguo sobre la buena

13 Mereminskaya, Elina, La Revista de Derecho, Santiago, Universidad Central de Chile, julio de 2003, pp. 255-273. 
fe que contiene la Convención de Viena de 1980, se ha ido interpretando cada vez más como regla general aplicable a los contratos; y cuarto, los Principios de Unidroit ratifican el papel preponderante que tiene la buena fe en la contratación internacional del presente.

Sobre estos últimos, podría decirse que no constituyen un tratado internacional, y que no representan, necesariamente, la posición de todos los Estados; sin embargo, expresan un lenguaje jurídico común para los actores del trafico internacional. Y es muy relevante que este trafico se realice dentro de los marcos morales de la buena fe, particularmente en un mundo que con frecuencia, privilegia el lucro por sobre los valores de la convivencia humana. 